\title{
Interpersonal conflict and counterproductive work behavior: the moderating roles of emotional intelligence and gender
}

\author{
Yasir Mansoor Kundi \\ IAE Aix-Marseille Graduate School of Management, CERGAM, \\ Aix-Marseille-University, Aix-en-Provence, France, and \\ Kamal Badar \\ School of Management, Victoria University of Wellington, \\ Wellington, New Zealand
}

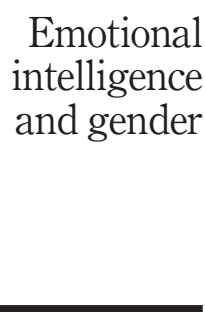

Received 26 October 2020 Revised 28 December 2020 20 January 2021 Accepted 23 January 2021

\begin{abstract}
Purpose - This paper aims to examine how interpersonal conflict at work might enhance employees' propensity to engage in counterproductive work behavior (CWB), as well as how this relationship might be attenuated by emotional intelligence. It also considers how the attenuating role of emotional intelligence might depend on employees' gender.
\end{abstract}

Design/methodology/approach - Survey data were collected from 193 employees working in different organizations in Pakistan.

Findings - Interpersonal conflict relates positively to CWB, but this relationship is weaker at higher levels of emotional intelligence. The negative buffering role of emotional intelligence is particularly strong among women as compared to men.

Practical implications - Given that individuals high in emotional intelligence are better at regulating their negative emotions, emotional intelligence training may be a powerful tool for reducing the hostility elicited among organizational members in response to interpersonal conflict and, consequently, their engagement in CWB.

Originality/value - This study uncovered the emotional mechanism that underlies the interpersonal conflict-CWB relationship by gender and makes suggestions to managers on minimizing the harmful effects of interpersonal conflict.

Keywords Emotional intelligence, Gender, Interpersonal conflict, Counterproductive work behavior Paper type Research paper

\section{Introduction}

Interpersonal conflict refers to "the manifestation of incompatibility, inconsistency, or disagreement between two or more interacting individuals" (Rahim, 2011, p. 87). The accumulated evidence suggests that interpersonal conflict is alarmingly common in the workplace (Tremmel et al., 2019; Yang et al., 2019). For example, Danielsson et al. (2015) reported that among thousands of participants in their studies over the past two years, $84 \%$

The authors wish to thank Professor Julie M. Hite for her meticulous proofreading and reviewing of the manuscript, which significantly improved the readability of the paper and Muhammad Sarfraz for collecting the data.

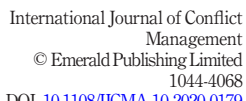
DOI 10.1108/IJCMA-10-2020-0179 
had reported being in some type of conflict situation with their coworkers, and about $50 \%$ had experienced it on a weekly basis. In addition to its high prevalence, interpersonal conflict has been found to have detrimental effects on employee job attitudes, health and well-being, nonwork life and performance (for reviews, see Bonaccio et al., 2019; Kuriakose et al., 2019; Notelaers et al., 2018; Ye et al., 2019). In addition to the negative effects of interpersonal conflict on individuals' work and health-related outcomes, Zhou et al. (2019) suggest that effects of interpersonal conflict at work can spill over to employees' negative work behaviors.

One important negative work behavior outcome of interpersonal conflict that has been examined is workplace deviance, also known as counterproductive work behavior (CWB) (Ma and Liu, 2019; O'Connor et al., 2017). CWB has been defined as "voluntary behavior that violates significant organizational norms and in so doing threatens the well-being of an organization, its members, or both" (Robinson and Bennett, 1995, p. 556). CWB has been shown to have detrimental effects on both organizational and individual outcomes such as Machiavellianism, frustration, job dissatisfaction, turnover intentions and reduced organizational performance and organizational citizenship behavior (OCB) (Bennett and Robinson, 2000; Chen and Wang, 2019; Dunlop and Lee, 2004), indicating the importance of exploring its potential antecedents and contextual factors to understand how it develops (De Clercq et al., 2021).

Accordingly, the current study aims to extend the previous research on negative outcomes of interpersonal conflict by examining the relationship between interpersonal conflict and CWB. Moreover, prior research shows that the effect of interpersonal conflict varies across individuals indicating the presence of moderators regulating the relationship between interpersonal conflict and its outcomes (Kuriakose et al., 2019). Therefore, in addition, we investigate a moderated-moderation analysis, considering two conditional effects - employees' emotional intelligence (high vs. low) and gender (men vs. women) - as potential moderators. Through examining these relationships, our study contributes to the current literature in three ways.

First, we contribute to the understanding of why interpersonal conflict at work is linked with CWB. Although Zhang et al. (2019) examined the impact of role conflict on employee $\mathrm{CWB}$, research into the interpersonal conflict-CWB relationship remains limited. Previous research suggests that interpersonal conflict at work fosters deviant behavior among employees (e.g. Ma and Liu, 2019; Zhang et al., 2019). Thus, on the basis of the social exchange theory (Blau, 1964), we answer recent calls to examine the effects of interpersonal conflict at work on employee negative work behaviors, specifically on CWB (Zhao et al., 2018).

Second, we examine how employee emotional intelligence, as a stable personal resourcedepleting job stressor, may moderate the interpersonal conflict-CWB relationship. Although previous studies have examined various contextual and job-related factors (e.g. social support, leadership and conflict management climate) as moderators of the relationship between workplace conflict and CWB (e.g. Chiu et al., 2015; Einarsen et al., 2018; Morgan et al., 2018), little knowledge exists about how individual differences may influence this relationship. On the basis of the conservation of resources (COR) theory (Hobfoll, 1989), we examine the moderating role of individuals' emotional intelligence - individuals' ability to understand and manage their own and others' emotions (Petrides and Furnham, 2006) - on the relationship between interpersonal conflict and CWB. Thus, we contribute to the theoretical understanding of boundary conditions related to the effects of interpersonal conflict (Gu et al., 2020; Park et al., 2020). 
Third, we contribute to research on negative outcomes of workplace conflict by testing whether the buffering role of emotional intelligence might be particularly salient across gender (men vs. women). Previous research suggests that the usefulness of personal resources for mitigating the positive effect of interpersonal conflict cannot be considered in isolation (Sharma et al., 2016). Research suggests that individuals differ fundamentally in their attitudes while dealing with others (Cinamon and Rich, 2002). For example, research has shown that women in particular are better than men in managing their emotions (McIntyre, 2010; Tsaousis and Kazi, 2013). Therefore, we examine gender as a contingency variable for the joint role of interpersonal conflict and emotional intelligence on employee CWB. By examining gender as a moderator of the interpersonal conflict-emotional intelligence interaction on individual CWB, our goal is to add new perspectives to the theoretical knowledge on interpersonal conflict-CWB linkages and indicate whether differences in individual attitudes and gender could be considered together to better understand these theoretical associations.

Finally, another novel feature of the current study is the context and the geographic location in which it is based. The present study was conducted in a developing Asian country context (i.e. Pakistan) where interpersonal conflict indicates a great threat to organization's performance (Shaukat et al., 2017) and has caused much stress to individual employees, intensifying conflict among their families and communities. Thus, the present study provides an opportunity to investigate whether internal conflict at work can manifest in negative work behaviors.

\section{Literature review and hypotheses development}

Interpersonal conflict and counterproductive work behavior

Interpersonal conflict refers to a negative interpersonal encounter characterized by a contentious exchange, hostility or aggression (Ilies et al., 2011). It is also referred to "the manifestation of incompatibility, inconsistency, or disagreement between two or more interacting individuals" (Rahim, 2011, p. 87). According to Thomas (1992, p. 653), interpersonal conflict is a "process that begins when one party perceives that the other has negatively affected, or is about to negatively affect, something that he or she cares about." Interpersonal conflict overlaps, yet is distinct from, several other negative workplace phenomena such as workplace bullying or workplace incivility, which are typically described as negative aggressive behaviors that are repeated and long-lasting. So far, only a handful of studies have examined the impact of interpersonal conflict on CWB (Bruk-Lee and Spector, 2006; Haq, 2011; Kessler et al., 2013), which warrants further attention.

CWB is a set of undesirable work behaviors that are intentional and harm, or intend to harm, the organization and/or its stakeholders (Gruys and Sackett, 2003). CWB is either directed toward the organization or its individuals (Bennett and Robinson, 2000). CWB directed toward the organization (CWB-O) includes stealing and damaging organizational property and withdrawal behaviors (Robinson and Bennett, 1995). On the other hand, CWB directed toward individuals (CWB-I) includes psychologically or psychically harming coworker, ignoring others and gossiping about peers (Bennett and Robinson, 2000). In the present study, we examine the effects of interpersonal conflict on CWB-O and CWB-I, rather than on CWB alone, given that previous research suggests that using CWB as an aggregate obscures its relationship with probable antecedents (Naseer et al., 2020). Additionally, researchers argued that both CWB-O and CWB-I contain a set of overlapping behaviors that are detrimental to the organization, with the nature and target of these behaviors being different (Spector and Fox, 2002). Therefore, although we expect similar relationships for CWB-O and CWB-I, we treat them separately so that possible differences may be identified. 
The current study uses social exchange theory (Blau, 1964) as a theoretical lens to understand the influence of interpersonal conflict on the respective employees' CWB. Social exchange theory is one of the most important conceptual paradigms used to understand individuals' behaviors in the workplace (Khattak et al., 2020). This theory suggests that individuals develop exchange relationships based on their experiences with others (Cook et al., 2013; Cropanzano and Mitchell, 2005; Emerson, 1976). In other words, the exchanges that take place between individuals are largely seen as interdependent and contingent on rewarding reactions from others in the social relationship and thus generate obligations (i.e. reciprocity) (Blau, 1964).

The concept of reciprocity is the essence of social exchange theory, which is often framed as a particular form of social exchange (Cropanzano and Mitchell, 2005). According to the norm of reciprocity, people who receive benefits from others feel obligated to reciprocate the same behavior (Gouldner, 1960). The norm of reciprocity is classified into two types (i.e. positive and negative norm of reciprocity). The norm of positive reciprocity induces an individual to return positive treatment for positive treatment, whereas the norm of negative reciprocity induces an individual to return negative treatment for negative treatment (Faldetta, 2020; Gouldner, 1960). According to Gouldner (1960), in the norm of negative reciprocity, individuals may perform negative behaviors against those who treat them inappropriately. In a recent study, Faldetta (2020) found that the norm of negative reciprocity can increase the likelihood that employees engage themselves in CWB. Low et al. (2019) also argued that the CWB is social behavior resulting from verbal transactions or exchanges (i.e. interpersonal conflict).

Accordingly, we draw on social exchange theory to explore the effects of interpersonal conflict at work on employee negative reactions, specifically CWB. We suggest that employees encountering conflicting experiences with others at work, in exchange, may return the favor by adopting CWB, including behaviors such as damaging or stealing company property, abusing coworkers and exposing colleagues to risk. Thus, we hypothesize the following:

\section{H1. Interpersonal conflict at work will be positively related to (a) CWB-O and (b) CWB-I.}

\section{Moderating role of emotional intelligence}

Emotional intelligence can be defined as "an ability to recognize the meanings of emotions and their relationships, and to reason and problem-solve on the basis of them" (Mayer et al., 1999, p. 267). Emotional intelligence also refers to a set of emotional abilities to understand, manage and use emotional information (Salovey and Mayer, 1990). Previous research has examined the moderating role of emotional intelligence on the relationships between different variables such as perceived stress and suicidal ideation (Abdollahi et al., 2016), personality and creativity (Jafri, 2020) and perceived threat of terrorism and workplace deviance (Shah et al., 2020). Results of previous studies suggest that emotional intelligence may also serve as a moderator on the relationship between interpersonal conflict and CWB. For instance, emotionally intelligent people are more capable of controlling themselves; therefore, they are more likely to avoid indulging in negative activities that may harm their organizations (Ugwu et al., 2017).

According to COR theory (Hobfoll, 1989), individuals feel stress when they experience actual resource loss, a lack of resource gain or a threat of resource loss. Resources refer to physical objects, individual characteristics, status and social ties (Cheng et al., 2012). According to Shaukat et al. (2017), conflict between individuals leads to loss of resources which then manifests in the form of stress. The COR theory also suggests that when 
individuals experience the threat of job resource loss, they strive to minimize the resource loss and prevent future resource loss. They make use of the existing resources to offset resource loss. Therefore, in line with COR theory, we argue that employees facing interpersonal conflict will experience resource loss and, as a result, they will strive to offset this resource loss through their existing resources, i.e. through their personal characteristics (Zhao and Guo, 2019). Thus, emotional intelligence as a personal trait (Cheng et al., 2012) could be a valuable resource that has a stress reducing effect and provides the potential to cope with the negative emotional reactions owing to interpersonal conflict.

Research has highlighted the importance of emotional intelligence for individuals dealing with stressful situations (Abdollahi et al., 2016). For instance, Sharma et al. (2016) argued that emotional intelligence plays a moderating role in the relationship between workplace conflict and individual emotional and behavioral reactions to such conflict. Soomro et al. (2019) argued that though stressful events trigger employee CWB; thus, how employees process their emotions induced by stressful events can significantly affect their engagement in CWB (Balogun et al., 2018; Ugwu et al., 2017). As stated by Chen et al. (2019), individuals with higher levels of emotional intelligence are better able to understand, regulate and make use of emotional information than those with lower levels. Therefore, employees will differ in the propensity to engage in CWB in the face of stressful events such as workplace conflict (Ma and Liu, 2019). Therefore, based on above arguments, we propose the following hypothesis:

H2. The relationships of interpersonal conflict with (a) CWB-O and (b) CWB-I will be negatively moderated by emotional intelligence, such that the positive relationship is weaker at higher levels of emotional intelligence.

\section{Role of gender}

Finally, we highlight the potential role of gender in relation to interpersonal conflict and CWB. The workplace conflict literature calls attention to gender differences in experiencing, perpetrating and responding to conflict at work (Gabriel et al., 2018; Graham et al., 2018; Hopwood et al., 2020). Gender has been found to correlate with CWB targeted at both individuals and organizations (Chiu et al., 2015; De Clercq et al., 2019) and considered as a potential moderator in the relationship between CWB and its predictors, such as personality, job stressors, negative affect and incivility (Samnani et al., 2014; Spector and Zhou, 2014; Welbourne and Sariol, 2017).

To date, very little research has examined the moderating role of gender on the relationship between work stressors and CWB. Interpersonal conflict is considered as one of the most important workplace stressors (Keenan and Newton, 1985). Bowling and Burns (2015) found that men were more likely than women to report engaging in greater amounts of CWB at high (versus low) levels of workplace stressors. They argued that gender differences may emerge because men have greater impulsivity than women (Szabó and Jones, 2019), with control being a central component of being able to refrain from engaging in CWB (Ju et al., 2019). Similarly, Chen et al. (2019) found that, as compared to women, men were more engaged in CWB.

Biological and social factors also explain gender differences in emotional intelligence (Fernández-Berrocal et al., 2012). According to the biological explanation, certain areas of the brain committed to emotional processing can be larger in women than men, which makes women better prepared to consider their own emotions and those of others (Baron-Cohen, 2002, 2003; Gur et al., 2002). According to the social explanation, women spend their social time connected to the emotional world (Candela Agulló et al., 2002) and, as compared to men, 
are more occupied with maintaining their and others' positive emotions to prevent the deterioration of interpersonal relations (Nolen-Hoeksema and Jackson, 2001). Therefore, we expect that the negative buffering effect of emotional intelligence on interpersonal conflict and CWB relation will be stronger for women with high emotional intelligence than men. Thus, we hypothesize the following:

H3. The negative buffering effect of emotional intelligence on interpersonal conflict and CWB [(a) CWB-O; (b) CWB-I] relation is moderated by gender, such that this negative buffering effect is stronger for women with high emotional intelligence than men.

\section{Methods}

\section{Study context}

Pakistan was selected as the empirical context because in Pakistan interpersonal conflict indicates a great threat to organization's performance (Shaukat et al., 2017). More specifically, Pakistan's media, information technology (IT) and telecom sectors have grown rapidly, suggesting a need for careful consideration of intra-organizational issues, such as interpersonal conflicts (Yousaf et al., 2020). Moreover, the high demand for services of interrelated sectors of media, IT, and telecom led to intensified competition putting pressure on those who work in these sectors to perform well. In turn, these employees generally face a heavy workload and came across different types of work-related conflict (Yousaf et al., 2020). Furthermore, gender and emotions are particularly important in a developing country like Pakistan, which is predominately a male-oriented society where issues of traditional negative gender-role stereotyping for women, sexual discrimination, domestic violence, fundamentalism and intimidation against women, lower literacy and employment rates for women are still prevalent (see UN report: The World's Women, 2010). Hence, it is expected that women in the labor force have to work in a traditional and sexually tense environment, and the presumed male domination of Pakistani organizations and numerical imbalance between genders (Fairhurst and Snavely, 1983; Kanter, 1977) most likely lead to great discomfort in cross-gender interactions (Badar et al., 2013; Hendrick, 1981). Women in Pakistani organizations, therefore, may rely on their emotional intelligence for better workrelated outcomes.

\section{Participants and procedure}

Invitations to participate in a survey were distributed among 300 employees working in 15 different organizations of Pakistan operating in the following interrelated sectors: media (e.g. print and electronic), IT (e.g. software and hardware) and telecom. The organizations were either a private, public or a multinational. The organizations were small and mid-sized, and the size of their workforces ranged from a low of 35 to a high of 140 . We approached all the organizations using our professional contacts and personally collected the data via paper-and-pencil method. Researchers distributed the questionnaires to participants before the lunch time and collected them after the lunch time, thus ensuring that participants could respond without the presence of the researchers.

As data were collected at single point in time, we adopted several procedural remedies as suggested by Podsakoff et al. (2003) to address the issue of common method bias. The procedural remedies included ensuring respondents' anonymity, stating in the cover letter that there were no right or wrong answers to the questions and that their candor was strongly encouraged, explaining the purpose of the study clearly, ordering items in a way to 
reduce priming effects and reducing item ambiguity by first completing a pilot study to reduce item ambiguity.

Out of 300 employees contacted, 211 questionnaires were received representing a response rate of $70.3 \%$. We excluded seven questionnaires as they displayed pattern responses (e.g. providing the same rating for all items) which can jeopardize the integrity of research findings (Meade and Craig, 2012) and 11 questionnaires owing to significant missing data. As a result, the final sample comprised 193 respondents, with a response rate of $64.3 \%$. Table 1 shows the respondents' demographic characteristics.

\section{Measures}

All the scales were taken from earlier research and presented in English as it is the official language of business organizations in Pakistan (Kundi et al., 2020). Unless stated otherwise, all items were rated on a five-point Likert scale ranging from 1 (strongly disagree) to 5 (strongly agree).

Interpersonal conflict. We measured interpersonal conflict with a five-item scale developed by Spector et al. (1988). Examples of items are "People are often rude to me at work" and "I often get into arguments with others at work." Cronbach's alpha of the scale was 0.89 .

Counterproductive work behavior. We measured CWB using 12 items taken from Aquino et al.'s (1999) workplace deviance scale, which consists of two dimensions. CWB-O was measured using seven items, for example, "I took undeserved breaks to avoid work." Cronbach's alpha $=0.93$. CWB-I was measured using five items, for example, "I swore at a coworker." Cronbach's alpha $=0.95$. Items were rated on a five-point Likert scale varying from $1=$ never to $5=$ very often. Cronbach's alpha of overall scale was 0.78 .

Emotional intelligence. We measured employees' emotional intelligence using 12 items borrowed from Wong and Law (2002) comprised of four subscales, namely, (i) self-emotion appraisal (i.e. "I have good understanding of my own emotions"; Cronbach's alpha $=0.87$ ), (ii) others' emotion appraisal (i.e. "I have good understanding of the emotions of people around me"; Cronbach's alpha $=0.91$ ), (iii) use of emotion (i.e. "I always tell myself I am a competent person"; Cronbach's alpha $=0.89$ ) and (iv) regulation of emotion (i.e. "I am able to

\begin{tabular}{llcc}
\hline Demographic & Description & Frequency & \% of total $n$ \\
\hline Gender & Male & 109 & 56.5 \\
& Female & 84 & 43.6 \\
Age (in years) & Less than 25 & 23 & 12.0 \\
& 25-35 & 115 & 59.5 \\
Education & More than 35 & 55 & 28.5 \\
& Bachelors & 41 & 21.2 \\
\multirow{3}{*}{ Work experience } & Masters & 106 & 54.9 \\
& MS/MPhil & 46 & 23.8 \\
Are you a manager? & Less than 5 & 116 & 60.2 \\
& 5-10 & 54 & 27.9 \\
& More than 10 & 23 & 11.9 \\
& No & 121 & 62.7 \\
& Yes & 56 & 37.3
\end{tabular}

Note: $n=193$

Emotional intelligence and gender 
control my temper and handle difficulties rationally"; Cronbach's alpha $=0.90$ ). Each subscale was measured with four items. Cronbach's alpha of overall scale was 0.96 .

Gender. Employee gender was self-reported, with women coded as 0 and men as 1.

Control variables. We controlled for employee age, education and work experience that might covary with CWB (De Clercq et al., 2019; Soomro et al., 2019). Previous research suggests that the emotional maturity that comes with age may make it less likely that older employees undertake negative work behaviors (Pletzer et al., 2017). Similarly, individual characteristics like education and work experience might also increase employees' confidence that they can protect themselves against negative repercussions that might arise from their deviant behaviors (De Clercq et al., 2019).

\section{Data analyses}

Following the guidelines of Anderson and Gerbing (1988), we first conducted confirmatory factor analysis (CFA) including all latent variables (i.e. interpersonal conflict, CWB-I, CWB-O and emotional intelligence) to check the discriminant validity of the measurement model. Afterward, we conducted descriptive analysis and estimated our intended model through ordinary least squares regressions using PROCESS macro-Model 3 (see Hayes, 2017 for details) through statistical package for the social sciences (25th edition). Finally, we used the moderatedmoderation model to test whether the relationship between interpersonal conflict and CWB, moderated by emotional intelligence, is moderated by gender (Figure 1). All estimated effects reported are unstandardized regression coefficients as recommended by Hayes (2017).

\section{Results}

\section{Preliminary analysis}

After the assessment of missing values and outliers, we tested the distribution of our variables and found that no variable approached skewness $>|3|$ (Chou and Bentler, 1995) or kurtosis values $>|10|$ (Kline, 2015), indicating the normal distribution of our data. Table 2 shows the mean, standard deviation and bivariate correlation among the study variables. None of the correlation coefficients exceeded the level of 0.70 , indicating the absence of multicollinearity among the variables. Interpersonal conflict was positively correlated with CWB-I $(r=0.46, p<0.01)$ and CWB-O $(r=0.41, p<0.01)$. Emotional intelligence was negatively correlated with interpersonal conflict $(r=-0.22, p<0.01)$ and CWB-I $(r=-0.25$, $p<0.01)$, whereas it was not correlated with CWB-O ( $r=-0.04$, ns).

\section{Confirmatory factor analysis}

Prior to hypotheses testing, we conducted a series of CFAs to examine the distinctiveness of each construct used in the present study. First, a CFA test was performed to measure the model

Figure 1.

Research model

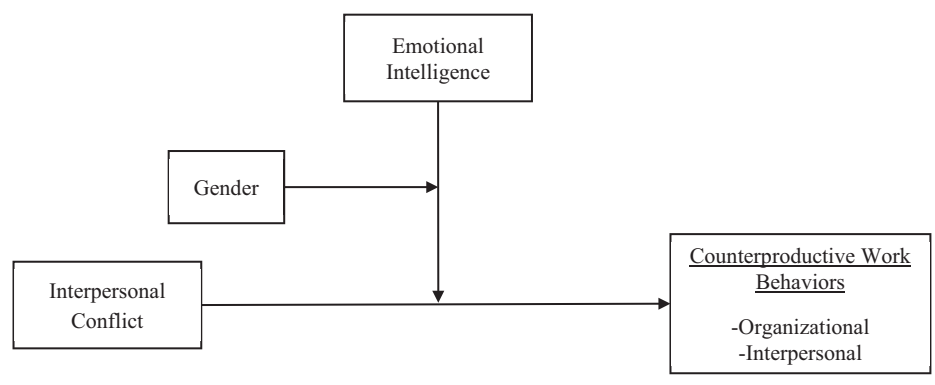




\begin{tabular}{lcccccccccccc}
\hline Variables & Mean & SD & AVE & ASV & 1 & 2 & 3 & 4 & 5 & 6 & 7 & 8 \\
\hline 1. Age & 2.17 & 0.62 & - & - & - & & & & & & \\
2. Work & & & & & & & & & & & \\
$\quad$ experience & 1.52 & 0.71 & - & - & $0.26^{* *}$ & - & & & & & \\
$\begin{array}{l}\text { 3. Education } \\
\text { 4. Gender }\end{array}$ & 2.03 & 0.67 & - & - & 0.13 & $0.26^{* *}$ & - & & & & \\
$\begin{array}{l}\text { 5. Interpersonal } \\
\quad \text { conflict }\end{array}$ & 0.56 & 0.49 & - & - & 0.03 & 0.09 & -0.013 & - & & & \\
$\begin{array}{l}\text { 6. Emotional } \\
\text { intelligence }\end{array}$ & 2.35 & 0.80 & 0.69 & 0.11 & -0.07 & 0.05 & -0.11 & 0.06 & - & & \\
7. CWB-I & 2.34 & 1.01 & 0.62 & 0.03 & $0.16^{*}$ & 0.04 & 0.07 & -0.10 & $-0.22^{* *}$ & - & \\
8. CWB-O & 2.55 & 1.01 & 0.78 & 0.76 & 0.18 & -0.12 & 0.07 & $-0.16^{*}$ & $0.15^{*}$ & $0.46^{* *}$ & $-0.25^{* *}$ & - \\
\end{tabular}

Emotional intelligence and gender

Notes: $n=193 ; \mathrm{AVE}=$ Average variance extracted, ASV $=$ Average shared variance; ${ }^{*} p<0.05, * * p<0.01$

fit of our intended four-factor model including interpersonal conflict, emotional intelligence, CWB-I and CWB-O. Considering the cutoff value criteria proposed by Hu and Bentler (1999), our intended model provided a good fit to the data $\left(\chi^{2}=794.9, \mathrm{df}=371\right.$, comparative fit index $=0.964$, root mean square error of approximation $=0.050$ and standardized root mean square residual $=0.049$ ).

Next, we compared our intended model against several alternative models including a three-factor model in which the two facets of CWB were combined together $\left(\Delta \chi^{2}=266.8\right.$, $\mathrm{df}=3$ ). Theoretically, CWB has two dimensions, namely, CWB-I (directed at individuals) and CWB-O (directed at organization). These two dimensions of CWB are theoretically distinct (Spector et al., 1988), although they are correlated. As a result of this correlation, the comparison with the three-factor alternative where CWB-I and CWB-O load on the same factor is a stringent test of the validity of our four-factor model. Another reason for testing a three-factor model is that very few studies of CWB use Asian samples, and we cannot be sure that individuals in our sample can empirically distinguish between the two aspects of CWB. Additionally, we compared the intended model with a two-factor model in which interpersonal conflict was combined with emotional intelligence and CWB-I was combined with CWB-O $\left(\Delta \chi^{2}=412.2, \mathrm{df}=5\right)$ and a one-factor model in which all variables were combined into one overall factor $\left(\Delta \chi^{2}=1,164.8, \mathrm{df}=6\right)$. The results of CFA (Table 3 ) showed that the intended four-factor model had a significantly better fit than the alternative models.

\begin{tabular}{lrccccc}
\hline Model & $\chi^{2}$ & df & RMSEA & CFI & SRMR & $\Delta \chi^{2}(\Delta$ df $)$ \\
\hline $\begin{array}{l}\text { Four-factor model: include IC, EI, } \\
\text { CWB-I and CWB-O }\end{array}$ & $794.9^{* *}$ & 371 & 0.050 & 0.964 & 0.049 & - \\
$\begin{array}{l}\text { Three-factor model: combines } \\
\text { CWB-I and CWB-O }\end{array}$ & $1,011.7^{* *}$ & 374 & 0.079 & 0.855 & 0.097 & $266.8(3)^{* *}$ \\
$\begin{array}{l}\text { Two-factor model: combines IC } \\
\text { with EI and CWB-I with CWB-O }\end{array}$ & $1,157.1^{* *}$ & 376 & 0.083 & 0.811 & 0.101 & $412.2(5)^{* *}$ \\
One-factor model & $1,909.7^{* *}$ & 377 & 0.121 & 0.613 & 0.119 & $1,164.8(6)^{* *}$
\end{tabular}

Notes: $\mathrm{EI}=$ Emotional Intelligence; IC $=$ Interpersonal conflict; $\mathrm{CWB}=$ Counterproductive work behaviors; $\mathrm{df}=$ Degree of freedom; RMSEA = Root mean square error of approximation; SRMR = Standardized root mean square residual; $\mathrm{CFI}=$ Comparative fit index; $* * p<0.01$

Table 3.

Fit statistics of measurement models 
We further assessed the construct validity through convergent validity and discriminant validity. Convergent validity was assessed through (i) factor loadings and (ii) average variance extracted (AVE) scores of each construct. According to Fornell and Larcker (1981) and Chin (2010), both AVE scores and factor loadings should be greater than 0.5 and 0.6, respectively. Our results showed that the AVE score of each construct was greater than the cutoff value of 0.5 , and the factor loadings of interpersonal conflict ranged from 0.81 to 0.87 , emotional intelligence ranged from 0.72 to 0.90 , CWB-I ranged from 0.87 to 0.94 and CWB-O ranged from 0.84 to 0.92 (all items significant at $p<0.001$ ). Discriminant validity was assessed by comparing the AVE of each construct with its average shared variance (ASV) score, i.e. mean of the squared correlations among constructs (Hair et al., 2011). All the values of AVE were higher than the ASV constructs, thereby supporting discriminant validity (Table 2 ).

\section{Common method variance}

To address potential issues with common method variance, both procedural and statistical remedies were applied. As mentioned earlier, we adopted procedural remedies such as ensuring respondents' anonymity, reducing ambiguity in the survey questions and ordering items in a way to reduce priming effects (Podsakoff et al., 2003). Statistically, we conducted an exploratory factor analysis with a principal axis factor extraction and direct oblimin rotation to ensure that each of the factors was perceived as distinct constructs by employees. We found that interpersonal conflict, emotional intelligence, CWB-I and CWB-O loaded cleanly on their respective constructs. We also used CFA marker variable technique to determine if there was a common method bias. We used Williams and Anderson's (1991) seven-item task performance scale (e.g. I perform my tasks that are expected of me) as a marker variable. Following Kundi et al. (2020), we ran a model in which the indicators of the study's variables were specified to load onto the latent marker variable $\left(\chi^{2}=1,657.3\right.$, $\mathrm{df}=522$ ) and compared it to a model in which they did not load onto the marker variable $\left(\chi^{2}=1,601.1, \mathrm{df}=568\right)$. The results showed that CMV was not present, and so it did not bias the parameters of our model, as evidenced by a nonsignificant $\chi^{2}$ difference test between the two models $\left(\Delta \chi^{2}=56.2, p=0.14\right)$.

\section{Hypotheses testing}

$H 1$ suggested that interpersonal conflict positively relates to (a) CWB-O and (b) CWB-I. As can be seen in Table 4 , interpersonal conflict positively predicted CWB-O $(\beta=0.43$, $p<0.01)$ and CWB-I $(\beta=0.36, p<0.01)$, supporting $H 1 a$ and $H 1 b$.

$H 2$ suggested that the relationships of interpersonal conflict with (a) CWB-O and (b) CWB-I will be moderated by emotional intelligence, such that the positive relationship is weaker at higher levels of emotional intelligence. Our results supported the buffering effect of emotional intelligence $(\beta=-0.51, p<0.01)$ on the interpersonal conflict and CWB-O relationship. Moreover, the buffering effect of emotional intelligence on the interpersonal conflict and CWB-I relationship was also significant $(\beta=-0.39, p<0.05)$. Therefore, $H 2 a$ and $H 2 b$ were supported. To clarify the nature of this interaction, Figures 2 and 3 plot the effects of interpersonal conflict on CWB at high and low levels of emotional intelligence, combined with a simple slope analysis (Aiken and West, 1991). The results of the simple slope analysis indicated that the relationship between interpersonal conflict and CWB-I was significant when emotional intelligence was low $(\beta=0.55, p<0.001)$ but became insignificant when it was high $(\beta=0.05$, ns), in further support of $H 2 a$. Similarly, the relationship between interpersonal conflict and CWB-O was significant when emotional 


\begin{tabular}{|c|c|c|c|c|}
\hline \multirow[b]{2}{*}{ Predictors } & \multicolumn{2}{|c|}{ CWB-I } & \multicolumn{2}{|c|}{ CWB-O } \\
\hline & $\beta$ & $\mathrm{SE}$ & $\beta$ & SE \\
\hline \multicolumn{5}{|l|}{ Control variables } \\
\hline Age & -0.16 & 0.09 & -0.23 & 0.17 \\
\hline Work experience & -0.01 & 0.08 & 0.08 & 0.15 \\
\hline Education & 0.09 & 0.08 & 0.01 & 0.10 \\
\hline \multicolumn{5}{|l|}{ Main variables } \\
\hline Interpersonal conflict (IC) & $0.36^{* *}$ & 0.09 & $0.43^{* *}$ & 0.11 \\
\hline Emotional intelligence (EI) & -0.02 & 0.05 & 0.11 & 0.07 \\
\hline Gender & $0.24^{*}$ & 0.14 & 0.05 & 0.21 \\
\hline $\mathrm{IC} \times \mathrm{EI}$ & $-0.51^{* *}$ & 0.06 & $-0.39^{*}$ & 0.08 \\
\hline IC $\times$ gender & -0.20 & 0.19 & -0.10 & 0.24 \\
\hline $\mathrm{EI} \times$ gender & $0.59^{* * *}$ & 0.20 & $0.62^{* *}$ & 0.20 \\
\hline $\mathrm{IC} \times \mathrm{EI} \times$ gender & $-0.40^{* *}$ & 0.14 & $-0.31^{*}$ & 0.17 \\
\hline$R^{2}$ & \multirow{2}{*}{\multicolumn{2}{|c|}{0.48}} & \multirow{2}{*}{\multicolumn{2}{|c|}{0.30}} \\
\hline$R^{2}$ change & & & & \\
\hline
\end{tabular}

Notes: $n=193 ;{ }^{*} p<0.05 ; \stackrel{* *}{*} p<0.01$

Emotional intelligence and gender

Table 4.

Ordinary least squares regression analysis predicting workplace deviance

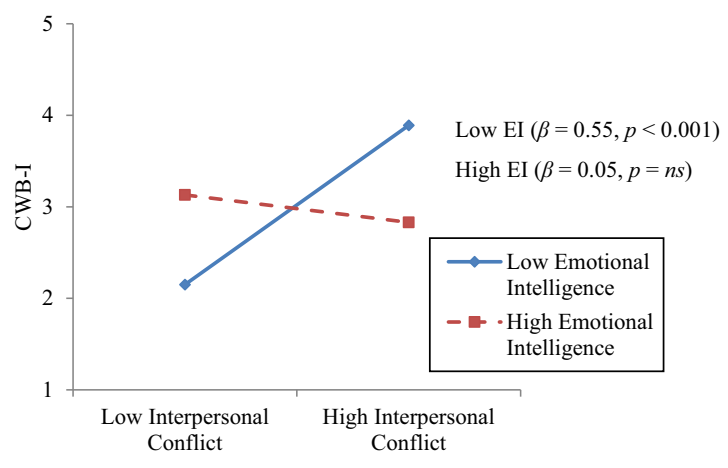

Figure 2. Interactive effects of emotional intelligence (EI) and interpersonal conflict on CWB-I

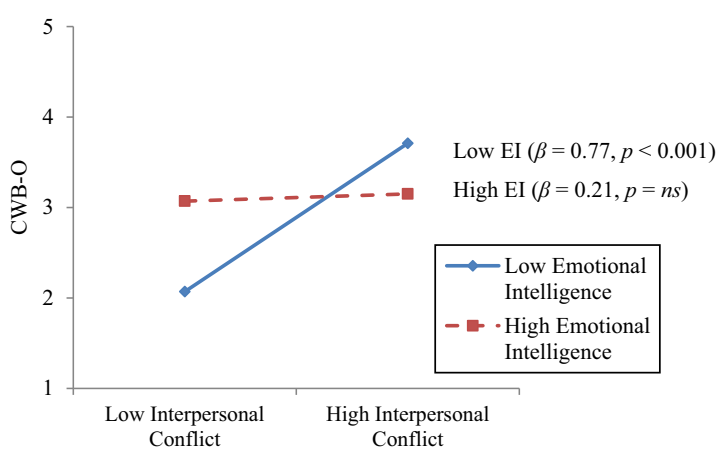

Figure 3. Interactive effects of emotional intelligence (EI) and interpersonal conflict on CWB-O 
IJCMA

Figure 4.

Three-way interactive relationship of interpersonal conflict, emotional intelligence and gender with CWB-I
Figure 5.

Three-way interactive relationship of interpersonal conflict, emotional intelligence and gender with CWB-O intelligence was low $(\beta=0.77, p<0.001)$ but became insignificant when it was high $(\beta=$ 0.21 , ns), in further support of $H 2 b$.

Finally, the results supported the three-way interaction effect among interpersonal conflict, emotional intelligence and gender predicted in $H 3 a$ and $H 3 b$. As predicted, there was a significant three-way interaction between interpersonal conflict, emotional intelligence and gender (all mean centered) in the prediction of CWB-O $(\beta=-0.31$, standard error $(\mathrm{SE})=0.17, p<0.01)$. The effect of negative interaction term between emotional intelligence and interpersonal conflict on CWB-O was stronger for women $(\beta=-0.57, p<0.01)$ than for men $(\beta=-0.28, p<0.01)$. Similarly, the three-way interaction between interpersonal conflict, emotional intelligence and gender (all mean centered) in the prediction of CWB-I was significant $(\beta=-0.40, \mathrm{SE}=0.14, p<0.01)$. The effect of negative interaction term between emotional intelligence and interpersonal conflict on CWB-I was stronger for women $(\beta=-0.45, p<0.01)$ than for men $(\beta=-0.19, p<0.05)$. Thus, $H 3 a$ and $H 3 b$ were supported. To demonstrate the result of the three-way interaction, we followed the graphical procedure of Aiken and West (1991) in Figures 4 and 5. As shown in Figures 4 and 5, the effects of interpersonal
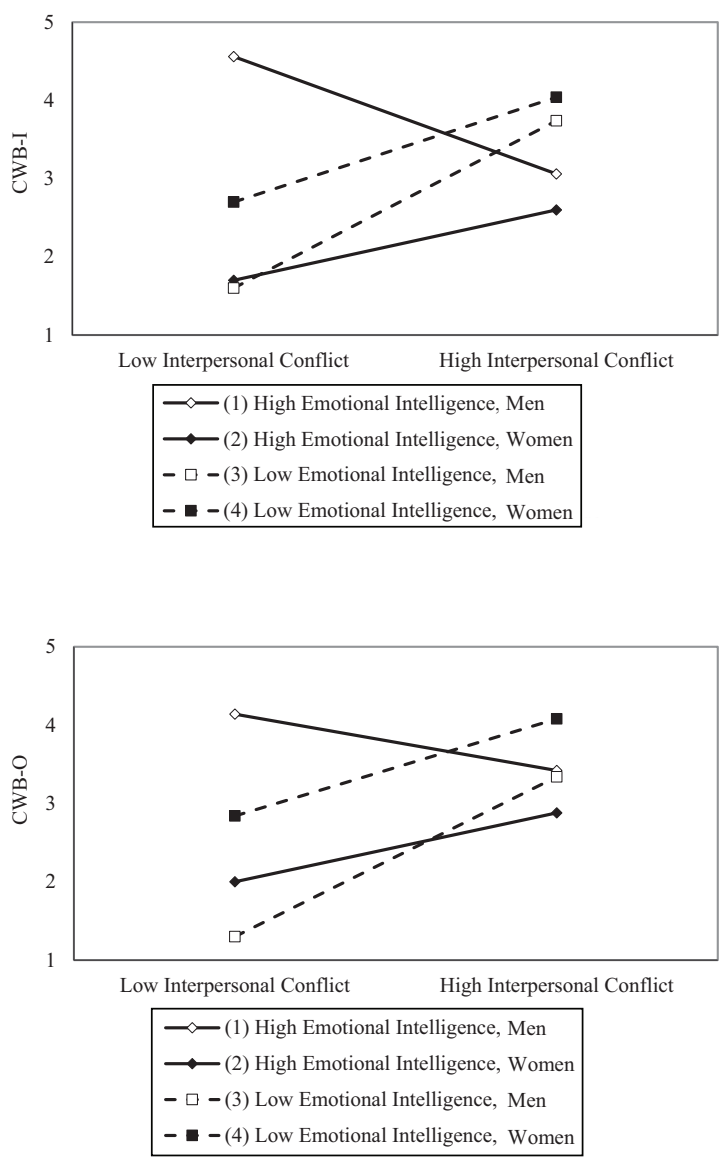
conflict on CWB-I and CWB-O are weaker in case of women as compared to men when emotional intelligence is higher than low. That is, women with higher levels of emotional intelligence are less involved in both CWB-I and CWB-O as compared to men as a result of interpersonal conflict at work.

Discussion

Drawing from social exchange and COR theories (Blau, 1964; Hobfoll, 1989), we investigated the impact of interpersonal conflict on CWB-O and CWB-I along with the moderating roles of emotional intelligence and gender. Our results showed that interpersonal conflict positively influences employee CWB-O and CWB-I ( $H 1 a$ and $H 1 b$ supported) likely owing to employees encountering conflicting experiences from others at work, returning the favor by adopting CWB (Low et al., 2019). Our results were consistent with findings reported by prior research. Bruk-Lee and Spector (2006), in their study of 133 dyads of full-time working participants at a university in the USA, tested the impact of conflict with supervisors and coworkers on CWB-O and CWB-I. They reported that conflict with coworkers significantly predicted CWB-I. Haq (2011), in his study of 264 employees from six organizations in Pakistan, tested the impact of interpersonal conflict on job outcomes. He found the positive impact of interpersonal conflict on interpersonal and organizational workplace deviance (similar to CWB). Kessler et al. (2013), in their study of 116 employee-coworker dyads, also found that interpersonal conflict led to negative emotions, which in turn led to CWB. Our findings may also align with Chen et al. (2005), who found positive outcomes of productive conflict when moderated by appropriate conflict management. The positive moderating influence of high emotional intelligence (like appropriate conflict management) on CWB provides a potential gender explanation for outcomes of interpersonal workplace conflict.

Furthermore, our results indicated that emotional intelligence negatively moderated the relationship between interpersonal conflict and CWB directed toward the organization and individuals (CWB-O and CWB-I) ( $H 2 a$ and $H 2 b$ supported) likely owing to employees high on emotional intelligence having less extreme emotional reactions to stressful events, such as interpersonal conflict, to help them cope with the event (Wong and Law, 2002). In the previous research, researchers also found a negative moderating role of emotional intelligence on the relationships between indirect supervisor conflict and employee deviant behavior (Ma and Liu, 2019), perceived threat of terrorism and workplace deviance (Shah et al., 2020), job pressures and auditors' judgment (Yang et al., 2019), perceived stress and suicidal ideation (Abdollahi et al., 2016) and job insecurity and emotional and behavioral reactions (Jordan et al., 2002), indicating the crucial role of emotional intelligence in controlling emotional reaction to stressful events which may lead to negative consequences.

Finally, our results demonstrated that the negative moderating effect of emotional intelligence on the relationship between interpersonal conflict and CWB-O and CWB-I was stronger for women than men ( $H 3 a$ and $H 3 b$ supported) likely owing to innate gender differences (Chen et al., 2019; Fernández-Berrocal et al., 2012; Ju et al., 2019; Szabó and Jones, 2019). More interestingly, while interpreting the slopes of the three-way interactive relationship of interpersonal conflict, emotional intelligence and gender with CWB-I and CWB-O (Figures 4 and 5), we found that the high emotional intelligence graph for men revealed a declining slope (more CWB at lower levels of conflict and less at a higher level of conflict), as compared to rest of the graphs which revealed increasing slopes. The reason for this result could be explained by the fact that in a masculine hierarchical culture like Pakistan, high emotional intelligence may give men complete freedom to engage in CWB-I and CWB-O unless there is an environment of pushback, i.e. an environment of high interpersonal conflict. Moreover, in such male-dominated cultures, emotional intelligence is 
critical in having men understand that deviant reactions to interpersonal conflict are not useful, so their exposure to such high levels of conflict diminishes CWB. That is, their emotional intelligence helps them see things in the opposite direction of what the culture prescribes.

\section{Theoretical implications}

Our study contributed toward theoretical advancements in interpersonal conflict-CWB literature in the following ways. First, on a theoretical level, our study provides additional support for the social exchange theory, demonstrating interpersonal conflict relates to greater employee CWB. This finding is in line with the previous empirical findings (Low et al., 2019). Furthermore, this study extends our previous knowledge regarding the potential depth of impact interpersonal conflict can have on employees as the damage created may reach even beyond a psychological level and materialize in behavioral reactions as well. Given these findings, it is critical that future research examine the impact that interpersonal conflict may have on other employee behavioral outcomes, such as work engagement, OCB and task performance. Further, different methodologies (e.g. longitudinal designs) can be used to better understand how the effects of interpersonal conflict unfold on behaviors through assessing across-time effects.

Second, by investigating the moderating roles of emotional intelligence, we contribute to the much-needed understanding of the boundary conditions of the effects of interpersonal conflict (Gu et al., 2020; Park et al., 2020). While few studies have studied the impact of interpersonal conflict on CWB (Bruk-Lee and Spector, 2006; Haq, 2011; Kessler et al., 2013), they lack an insight about potential moderators between the relationship of interpersonal conflict and CWB. An exceptional study by Ma and Liu (2019) investigated the moderating role of emotional intelligence on the relationship between indirect supervisor conflict and CWB. This study contributes to the understanding about the moderating role of emotional intelligence between interpersonal conflict and CWB.

Finally, to the best of our knowledge, no previous study has examined the moderating role of gender on the interpersonal conflict-emotional intelligence interaction on individuals' CWB. Based on prior research, which had shown significant differences in emotional intelligence between men and women (Fernández-Berrocal et al., 2012; Gur et al., 2002; Nolen-Hoeksema and Jackson, 2001), we had good reasons to believe that gender differences need to be accounted for to better understand the interplay of conflict, CWB and emotional intelligence. Therefore, by testing gender as a moderator of the interpersonal conflictemotional intelligence interaction on individuals' CWB, we contributed toward the conflictCWB and emotional intelligence literature by illustrating that differences in individuals attitudes and demographics should be considered together to better understand the conflictCWB relationship.

\section{Practical implications}

In the present study, we found that interpersonal conflict can trigger CWB among employees, making interpersonal conflict very costly to the organization and its members. Thus, organizations should attempt to reduce interpersonal conflict among employees by implementing appropriate interventions. For example, a job redesign and provision for ombudsman might help avoid/reduce the occurrence of interpersonal conflict (Rahim, 1985). In addition, managers may consider putting in place a protocol to detect and intervene in interpersonal conflicts when they emerge. The absence of early intervention makes it difficult to prevent conflict escalation into a stressful and resource-draining situation that will lead to CWB-O and CWB-1. Moreover, our findings suggest that when emotional intelligence is low 
CWB appears to be a higher potential risk for both employees and organizations than when emotional intelligence is high. Thus, recruiting emotionally intelligent employees and providing training programs that develop emotional control capabilities in employees should therefore be a key priority for organizations. However, such interventions can be very costly and time-consuming. Thus, managers should focus more on reducing tensions and conflicts among the employees (Rahim, 1985). This could be achieved by creating awareness among the employees about the detrimental effects of conflict among employee (Ilies et al., 2011), reducing adverse work events and fostering trust among group members (Turesky et al., 2020) and providing/developing a supportive work environment where individuals could be motivated to seek and provide social support to avert interpersonal conflicts.

We also found that as compared to men, women are less likely to be involved in CWB when emotional intelligence is high. Therefore, gender-based employee training to hone employees' emotional intelligence skills can be an alternative to conflict intervention strategies (Hodzic et al., 2018; Mattingly and Kraiger, 2019; Slaski and Cartwright, 2003). Furthermore, we found that male employees with higher emotional intelligence were more engaged in CWB when interpersonal conflict was lower than higher. Thus, managers working in organizations where both interpersonal conflict and CWB are present should adopt a balancing approach where the interpersonal conflict and CWB should be balanced. In other words, managers should work parallel on reducing the conflict among employees and controlling the CWB at work.

\section{Limitations and directions for future research}

Some limitations of our study may be addressed in future research. First, the crosssectional data do not provide sufficiently conclusive evidence of causality for the relations of interest. This limitation may be addressed by empirically testing our model using longitudinal or multiwave/cross-lagged data, i.e. measuring the predictor and outcomes variables at different time points (Ma and Liu, 2019). Second, our construct for CWB included items for both interpersonal and organizational CWB; however, both dimensions of deviance can have different antecedents and consequences which need to be explored in future research. Third, while we focused on the moderation of the emotional intelligence of supervisees, future research could explore how emotional intelligence of supervisors may serve to preempt interpersonal conflict and manage deviant behavior. Fourth, while we focused on the role of gender in the interplay of conflict, CWB and emotional intelligence, future research could study the role of age or generation (e.g. generation X or Y). Fifth, Chen et al. (2005) state that appropriate management of conflicts can induce creative problem-solving, interpersonal relationship satisfaction and lead to improved efficiency. Future research could also explore potential positive outcomes of interpersonal conflict. Finally, the present study centers on a sample of Pakistan-based organizations, so cultural factors may be relevant. Even though our theoretical arguments are not specific to this country, Pakistani culture, which scores high on collectivism, power distance and masculinity (Hofstede, 2011), might impact gender and individuals' emotions. For instance, research shows that control of emotion is encouraged in high power distance and collectivistic cultures (Gunkel et al., 2014). Similarly, Hofstede suggests that gender differences are likely to be more pronounced in masculine cultures than feminine cultures (Edgar et al., 2020). Thus, cross-country comparisons could reveal the potential buffering role of emotional intelligence and gender in the interpersonal conflict and CWB relation, in different cultural contexts. 


\section{Conclusion}

In conclusion, this work contributes to the literature relating interpersonal conflict, emotional intelligence and gender to CWB. We find that emotional intelligence and gender shape how employees respond to interpersonal conflict, such that employees with higher interpersonal conflict and higher emotional intelligence evidenced lower CWB. Further, we find that women as compared to men were less likely to be engaged in CWB when faced with interpersonal conflict at high (versus low) levels of emotional intelligence.

\section{References}

Abdollahi, A., Carlbring, P., Khanbani, M. and Ghahfarokhi, S.A. (2016), "Emotional intelligence moderates perceived stress and suicidal ideation among depressed adolescent inpatients", Personality and Individual Differences, Vol. 102, pp. 223-228.

Aiken, L.S. and West, S.G. (1991), Multiple Regression: Testing and Interpreting Interactions, Sage Publications.

Anderson, J.C. and Gerbing, D.W. (1988), "Structural equation modeling in practice: a review and recommended two-step approach", Psychological Bulletin, Vol. 103 No. 3, p. 411.

Aquino, K., Lewis, M.U. and Bradfield, M. (1999), "Justice constructs, negative affectivity, and employee deviance: a proposed model and empirical test", Journal of Organizational Behavior, Vol. 20 No. 7, pp. 1073-1091.

Badar, K., Hite, J.M. and Badir, Y.F. (2013), "Examining the relationship of co-authorship network centrality and gender on academic research performance: the case of chemistry researchers in Pakistan", Scientometrics, Vol. 94 No. 2, pp. 755-775.

Balogun, A.G., Oluyemi, T.S. and Afolabi, O.A. (2018), "Psychological contract breach and workplace deviance: does emotional intelligence matter?", Journal of Psychology in Africa, Vol. 28 No. 1, pp. 8-14.

Baron-Cohen, S. (2002), "The extreme male brain theory of autism”, Trends in Cognitive Sciences, Vol. 6 No. 6, pp. 248-254.

Baron-Cohen, S. (2003), Men, Women and the Extreme Male Brain, Penguin, London.

Bennett, R.J. and Robinson, S.L. (2000), "Development of a measure of workplace deviance", Journal of Applied Psychology, Vol. 85 No. 3, p. 349.

Blau, P.M. (1964), Exchange and Power in Social Life, Wiley, New York, NY.

Bonaccio, S., Lapierre, L.M. and O'Reilly, J. (2019), “Creating work climates that facilitate and maximize the benefits of disclosing mental health problems in the workplace", Organizational Dynamics, Vol. 48 No. 3, pp. 113-122.

Bowling, N.A. and Burns, G.N. (2015), "Sex as a moderator of the relationships between predictor variables and counterproductive work behavior", Journal of Business and Psychology, Vol. 30 No. 1, pp. 193-205.

Bruk-Lee, V. and Spector, P.E. (2006), "The social stressors-counterproductive work behaviors link: are conflicts with supervisors and coworkers the same?", Journal of Occupational Health Psychology, Vol. 11 No. 2, p. 145.

Candela Agulló, C., Barberá Heredia, E., Ramos López, A. and Sarrió Catalá, M. (2002), "Inteligencia emocional y la variable género", Revista Electrónica de Emoción y Motivación REME, Vol. 5 No. 10, pp. 167-182.

Chen, H.-T. and Wang, C.-H. (2019), "Incivility, satisfaction and turnover intention of tourist hotel chefs: moderating effects of emotional intelligence", International Journal of Contemporary Hospitality Management, Vol. 31 No. 5, pp. 2034-2053.

Chen, G., Liu, C. and Tjosvold, D. (2005), "Conflict management for effective top management teams and innovation in China", Journal of Management Studies, Vol. 42 No. 2, pp. 277-300. 
Chen, H.X., Xu, X. and Phillips, P. (2019), "Emotional intelligence and conflict management styles", International Journal of Organizational Analysis, Vol. 27 No. 3, pp. 458-470.

Cheng, T., Huang, G., Lee, C. and Ren, X. (2012), "Longitudinal effects of job insecurity on employee outcomes: the moderating role of emotional intelligence and the leader-member exchange", Asia Pacific Journal of Management, Vol. 29 No. 3, pp. 709-728.

Chin, W.W. (2010), "How to write up and report PLS analyses", Handbook of Partial Least Squares, Springer, pp. 655-690.

Chiu, S.F., Yeh, S.-P. and Huang, T.C. (2015), "Role stressors and employee deviance: the moderating effect of social support", Personnel Review, Vol. 44 No. 2, pp. 308-324.

Chou, C.P. and Bentler, P.M. (1995), Estimates and Tests in Structural Equation Modeling, Sage Publications.

Cinamon, R.G. and Rich, Y. (2002), "Gender differences in the importance of work and family roles: implications for work-family conflict”, Sex Roles, Vol. 47 Nos 11/12, pp. 531-541.

Cook, K.S., Cheshire, C., Rice, E.R. and Nakagawa, S. (2013), "Social exchange theory", Handbook of Social Psychology, Springer, pp. 61-88.

Cropanzano, R. and Mitchell, M.S. (2005), "Social exchange theory: an interdisciplinary review", Journal of Management, Vol. 31 No. 6, pp. 874-900.

Danielsson, C.B., Bodin, L., Wulff, C. and Theorell, T. (2015), "The relation between office type and workplace conflict: a gender and noise perspective", Journal of Environmental Psychology, Vol. 42, pp. 161-171.

De Clercq, D., Haq, I.U. and Azeem, M.U. (2019), “Time-related work stress and counterproductive work behavior”, Personnel Review, Vol. 48 No. 7, pp. 1756-1781.

De Clercq, D., Kundi, Y.M., Sardar, S. and Shahid, S. (2021), "Perceived organizational injustice and counterproductive work behaviours: mediated by organizational identification, moderated by discretionary human resource practices", Personnel Review, Vol. ahead-of-print No. ahead-of-print.

Dunlop, P.D. and Lee, K. (2004), "Workplace deviance, organizational citizenship behavior, and business unit performance: the bad apples do spoil the whole barrel", Journal of Organizational Behavior, Vol. 25 No. 1, pp. 67-80.

Edgar, F., Blaker, N.M. and Everett, A.M. (2020), "Gender and job performance: linking the high performance work system with the ability-motivation-opportunity framework", Personnel Review, Vol. 50 No. 1, doi: 10.1108/PR-10-2019-0577.

Einarsen, S., Skogstad, A., Rørvik, E., Lande, A.B. and Nielsen, M.B. (2018), "Climate for conflict management, exposure to workplace bullying and work engagement: a moderated mediation analysis", The International Journal of Human Resource Management, Vol. 29 No. 3, pp. 549-570.

Emerson, R.M. (1976), “Social exchange theory”, Annual Review of Sociology, Vol. 2 No. 1, pp. 335-362.

Fairhurst, G.T. and Snavely, B.K. (1983), "A test of the social isolation of male tokens”, Academy of Management Journal, Vol. 26, pp. 353-361.

Faldetta, G. (2020), “Abusive supervision and workplace deviance: the role of negative reciprocity", International Journal of Organizational Analysis.

Fernández-Berrocal, P., Cabello, R., Castillo, R. and Extremera, N. (2012), "Gender differences in emotional intelligence: the mediating effect of age”, Behavioral Psychology, Vol. 20 No. 1, pp. 77-89.

Fornell, C. and Larcker, D.F. (1981), Structural Equation Models with Unobservable Variables and Measurement Error: Algebra and Statistics, SAGE Publications Sage CA, Los Angeles, CA.

Gabriel, A.S., Butts, M.M., Yuan, Z., Rosen, R.L. and Sliter, M.T. (2018), "Further understanding incivility in the workplace: the effects of gender, agency, and communion", Journal of Applied Psychology, Vol. 103 No. 4, p. 362. 
Gouldner, A. (1960), "The norm of reciprocity: a preliminary statement”, American Sociological Review, Vol. 25 No. 2, pp. 161-178.

Graham, K.A., Dust, S.B. and Ziegert, J.C. (2018), "Supervisor-employee power distance incompatibility, gender similarity, and relationship conflict: a test of interpersonal interaction theory", Journal of Applied Psychology, Vol. 103 No. 3, pp. 334-346.

Gruys, M.L. and Sackett, P.R. (2003), "Investigating the dimensionality of counterproductive work behavior", International Journal of Selection and Assessment, Vol. 11 No. 1, pp. 30-42.

$\mathrm{Gu}$, Y., You, X. and Wang, R. (2020), "Job demands and emotional labor as antecedents of female preschool teachers' work-to-family conflict: the moderating role of job resources", International Journal of Stress Management, Vol. 27 No. 1, pp. 23-34.

Gunkel, M., Schlägel, C. and Engle, R.L. (2014), "Culture's influence on emotional intelligence: an empirical study of nine countries", Journal of International Management, Vol. 20 No. 2, pp. 256-274.

Gur, R.C., Gunning-Dixon, F., Bilker, W.B. and Gur, R.E. (2002), "Sex differences in temporo-limbic and frontal brain volumes of healthy adults", Cerebral Cortex, Vol. 12 No. 9, pp. 998-1003.

Hair, J.F., Ringle, C.M. and Sarstedt, M. (2011), "PLS-SEM: Indeed a silver bullet”, Journal of Marketing Theory and Practice, Vol. 19 No. 2, pp. 139-152.

Haq, I.U. (2011), "The impact of interpersonal conflict on job outcomes: mediating role of perception of organizational politics", Procedia-Social and Behavioral Sciences, Vol. 25, pp. 287-310.

Hayes, A.F. (2017), Introduction to Mediation, Moderation, and Conditional Process Analysis: A Regression-Based Approach, Guilford Publications.

Hendrick, S.S. (1981), “Why women don't succeed”, National Business Employment Weekly, Vol. 40, pp. 9-11.

Hobfoll, S.E. (1989), "Conservation of resources: a new attempt at conceptualizing stress", American Psychologist, Vol. 44 No. 3, p. 513.

Hodzic, S., Scharfen, J., Ripoll, P., Holling, H. and Zenasni, F. (2018), "How efficient are emotional intelligence trainings: a meta-analysis", Emotion Review, Vol. 10 No. 2, pp. 138-148.

Hofstede, G. (2011), "Insights on Hofstede's research into national and organisational culture”, available at: www.hofstede-insights.com/country-comparison/pakistan/ (accessed 7 December 2020).

Hopwood, C.J., Harrison, A.L., Amole, M., Girard, J.M., Wright, A.G., Thomas, K.M., Sadler, P., et al. (2020), "Properties of the continuous assessment of interpersonal dynamics across sex, level of familiarity, and interpersonal conflict", Assessment, Vol. 27 No. 1, pp. 40-56.

Hu, L. and Bentler, P.M. (1999), "Cutoff criteria for fit indexes in covariance structure analysis: conventional criteria versus new alternatives", Structural Equation Modeling: A Multidisciplinary Journal, Vol. 6 No. 1, pp. 1-55.

Ilies, R., Johnson, M.D., Judge, T.A. and Keeney, J. (2011), “A within-individual study of interpersonal conflict as a work stressor: dispositional and situational moderators”, Journal of Organizational Behavior, Vol. 32 No. 1, pp. 44-64.

Jafri, M.H. (2020), "Moderating role of emotional intelligence on personality - employee creativity relationship", Management and Labour Studies, Vol. 45 No. 1, pp. 15-30.

Jordan, P.J., Ashkanasy, N.M. and Hartel, C.E. (2002), "Emotional intelligence as a moderator of emotional and behavioral reactions to job insecurity", Academy of Management Review, Vol. 27 No. 3, pp. 361-372.

Ju, D., Xu, M., Qin, X. and Spector, P. (2019), “A multilevel study of abusive supervision, norms, and personal control on counterproductive work behavior: a theory of planned behavior approach", Journal of Leadership and Organizational Studies, Vol. 26 No. 2, pp. 163-178.

Kanter, R.M. (1977), "Some effects of proportions on group life - skewed sex-ratios and responses to token women”, American Journal of Sociology, Vol. 82 No. 5, pp. 965-990. 
Keenan, A. and Newton, T.J. (1985), "Stressful events, stressors and psychological strains in young professional engineers", Journal of Organizational Behavior, Vol. 6 No. 2, pp. 151-156.

Kessler, S.R., Bruursema, K., Rodopman, B. and Spector, P.E. (2013), "Leadership, interpersonal conflict, and counterproductive work behavior: an examination of the stressor-strain process", Negotiation and Conflict Management Research, Vol. 6 No. 3, pp. 180-190.

Khattak, M.N., Zolin, R. and Muhammad, N. (2020), "The combined effect of perceived organizational injustice and perceived politics on deviant behaviors", International Journal of Conflict Management.

Kline, R.B. (2015), Principles and Practice of Structural Equation Modeling, Guilford publications.

Kundi, Y.M., Aboramadan, M., Elhamalawi, E.M.I. and Shahid, S. (2020), "Employee psychological well-being and job performance: exploring mediating and moderating mechanisms", International Journal of Organizational Analysis.

Kundi, Y.M., Hollet-Haudebert, S. and Peterson, J. (2020), "Linking protean and boundaryless career attitudes to subjective career success: a serial mediation model", Journal of Career Assessment, p. 1069072720959782.

Kuriakose, V., Sreejesh, S., Jose, H., Anusree, M.R. and Jose, S. (2019), "Process conflict and employee well-being", International Journal of Conflict Management, Vol. 30 No. 4, pp. 462-489.

Low, Y.M., Sambasivan, M. and Ho, J.A. (2019), "Impact of abusive supervision on counterproductive work behaviors of nurses", Asia Pacific Journal of Human Resources, Vol. 57 No. 2, pp. 189-215.

Ma, J. and Liu, C. (2019), "The moderating effect of emotional intelligence on the relationship between supervisor conflict and employees' counterproductive work behaviors", International Journal of Conflict Management, Vol. 30 No. 2, pp. 227-245.

Mattingly, V. and Kraiger, K. (2019), "Can emotional intelligence be trained? A meta-analytical investigation”, Human Resource Management Review, Vol. 29 No. 2, pp. 140-155.

Mayer, J.D., Caruso, D.R. and Salovey, P. (1999), "Emotional intelligence meets traditional standards for an intelligence", Intelligence, Vol. 27 No. 4, pp. 267-298.

McIntyre, H.H. (2010), "Gender differences in the nature and linkage of higher-order personality factors to trait and ability emotional intelligence", Personality and Individual Differences, Vol. 48 No. 5, pp. 617-622.

Meade, A.W. and Craig, S.B. (2012), "Identifying careless responses in survey data", Psychological Methods, Vol. 17 No. 3, p. 437.

Morgan, W.B., Perry, S.J. and Wang, Y. (2018), "The angry implications of work-to-family conflict: examining effects of leadership on an emotion-based model of deviance", Journal of Vocational Behavior, Vol. 108, pp. 13-27.

Naseer, S., Raja, U., Syed, F. and Baig, M.U.A. (2020), "When and why organizational cynicism leads to CWBs", Personnel Review, Vol. 50 No. 1.

Nolen-Hoeksema, S. and Jackson, B. (2001), "Mediators of the gender difference in rumination", Psychology of Women Quarterly, Vol. 25 No. 1, pp. 37-47.

Notelaers, G., Van der Heijden, B., Guenter, H., Nielsen, M.B. and Einarsen, S.V. (2018), "Do interpersonal conflict, aggression and bullying at the workplace overlap? A latent class modeling approach", Frontiers in Psychology, Vol. 9, p. 1743.

O'Connor, P.J., Stone, S., Walker, B.R. and Jackson, C.J. (2017), "Deviant behavior in constrained environments: sensation-seeking predicts workplace deviance in shallow learners", Personality and Individual Differences, Vol. 108, pp. 20-25.

Park, S., Mathieu, J.E. and Grosser, T.J. (2020), “A network conceptualization of team conflict”, Academy of Management Review, Vol. 45 No. 2, pp. 352-375.

Petrides, K.V. and Furnham, A. (2006), "The role of trait emotional intelligence in a gender-specific model of organizational variables 1", Journal of Applied Social Psychology, Vol. 36 No. 2, pp. 552-569. 
Pletzer, J.L., Oostrom, J. and Voelpel, S.C. (2017), "Age differences in workplace deviance: a metaanalysis", Academy of Management Proceedings, Academy of Management Briarcliff Manor, New York, NY, Vol. 2017, p. 11475.

Podsakoff, P.M., MacKenzie, S.B., Lee, J.-Y. and Podsakoff, N.P. (2003), "Common method biases in behavioral research: a critical review of the literature and recommended remedies", Journal of Applied Psychology, Vol. 88 No. 5, pp. 879-903.

Rahim, M.A. (1985), “A strategy for managing conflict in complex organizations”, Human Relations, Vol. 38 No. 1, pp. 81-89.

Robinson, S.L. and Bennett, R.J. (1995), "A typology of deviant workplace behaviors: a multidimensional scaling study", Academy of Management Journal, Vol. 38 No. 2, pp. 555-572.

Salovey, P. and Mayer, J.D. (1990), "Emotional intelligence", Imagination, Cognition and Personality, Vol. 9 No. 3, pp. 185-211.

Samnani, A.-K., Salamon, S.D. and Singh, P. (2014), "Negative affect and counterproductive workplace behavior: the moderating role of moral disengagement and gender", Journal of Business Ethics, Vol. 119 No. 2, pp. 235-244.

Shah, S.J., Shah, S.A.A., Ullah, R. and Shah, A.M. (2020), "Deviance due to fear of victimization: 'emotional intelligence' a game-changer", International Journal of Conflict Management, Vol. 31 No. 5, pp. 687-707.

Sharma, J., Dhar, R.L. and Tyagi, A. (2016), "Stress as a mediator between work-family conflict and psychological health among the nursing staff: moderating role of emotional intelligence", Applied Nursing Research, Vol. 30, pp. 268-275.

Shaukat, R., Yousaf, A. and Sanders, K. (2017), "Examining the linkages between relationship conflict, performance and turnover intentions: role of job burnout as a mediator", International Journal of Conflict Management, Vol. 28 No. 1, pp. 4-23.

Slaski, M. and Cartwright, S. (2003), "Emotional intelligence training and its implications for stress, health and performance", Stress and Health, Vol. 19 No. 4, pp. 233-239.

Soomro, S.A., Kundi, Y.M. and Kamran, M. (2019), "Antecedents of workplace deviance: role of job insecurity, work stress, and ethical work climate”, Problemy Zarzadzania, Vol. 17 No. 6, pp. 74-90.

Spector, P.E. and Fox, S. (2002), "An emotion-centered model of voluntary work behavior: some parallels between counterproductive work behavior and organizational citizenship behavior", Human Resource Management Review, Vol. 12 No. 2, pp. 269-292.

Spector, P.E. and Zhou, Z.E. (2014), "The moderating role of gender in relationships of stressors and personality with counterproductive work behavior", Journal of Business and Psychology, Vol. 29 No. 4, pp. 669-681.

Spector, P.E., Dwyer, D.J. and Jex, S.M. (1988), "Relation of job stressors to affective, health, and performance outcomes: a comparison of multiple data sources", Journal of Applied Psychology, Vol. 73 No. 1, p. 11.

Szabó, E. and Jones, D.N. (2019), "Gender differences moderate Machiavellianism and impulsivity: implications for dark triad research", Personality and Individual Differences, Vol. 141, pp. 160-165.

Thomas, K.W. (1992), "Conflict and conflict management: reflections and update", Journal of Organizational Behavior, Vol. 13 No. 3, pp. 265-274.

Tremmel, S., Sonnentag, S. and Casper, A. (2019), "How was work today? Interpersonal work experiences, work-related conversations during after-work hours, and daily affect", Work and Stress, Vol. 33 No. 3, pp. 247-267.

Tsaousis, I. and Kazi, S. (2013), "Factorial invariance and latent mean differences of scores on trait emotional intelligence across gender and age", Personality and Individual Differences, Vol. 54 No. 2, pp. 169-173. 
Turesky, E.F., Smith, C.D. and Turesky, T.K. (2020), "A call to action for virtual team leaders: practitioner perspectives on trust, conflict and the need for organizational support", Organization Management Journal, Vol. 17 Nos 4/5.

Ugwu, L.I., Enwereuzor, I.K., Fimber, U.S. and Ugwu, D.I. (2017), "Nurses' burnout and counterproductive work behavior in a Nigerian sample: the moderating role of emotional intelligence”, International Journal of Africa Nursing Sciences, Vol. 7, pp. 106-113.

Welbourne, J.L. and Sariol, A.M. (2017), "When does incivility lead to counterproductive work behavior? Roles of job involvement, task interdependence, and gender", Journal of Occupational Health Psychology, Vol. 22 No. 2, p. 194.

Wong, C.-S. and Law, K.S. (2002), "The effects of leader and follower emotional intelligence on performance and attitude: an exploratory study", The Leadership Quarterly, Vol. 13 No. 3, pp. 243-274.

Yang, S.W., Trincardo, F., Labianca, G. and Agneessens, F. (2019), "Negative ties at work", Social Networks at Work, Routledge, New York, NY.

Ye, Z., Liu, H. and Gu, J. (2019), "Relationships between conflicts and employee perceived job performance", International Journal of Conflict Management, Vol. 30 No. 5, pp. 706-728.

Yousaf, A., Shaukat, R. and Umrani, W.A. (2020), "Linkages between group level task conflict and individual level outcomes in non-routine technical jobs", International Journal of Conflict Management, Vol. 32 No. 1, pp. 158-176.

Zhang, Y., Crant, J.M. and Weng, Q. (2019), "Role stressors and counterproductive work behavior: the role of negative affect and proactive personality", International Journal of Selection and Assessment, Vol. 27 No. 3, pp. 267-279.

Zhao, H. and Guo, L. (2019), "Abusive supervision and hospitality employees' helping behaviors: the joint moderating effects of proactive personality and ability to manage resources", International Journal of Contemporary Hospitality Management, Vol. 31 No. 4, pp. 1977-1994.

Zhao, J., Xiao, S., Mao, J. and Liu, W. (2018), "The buffering effect of Machiavellianism on the relationship between role conflict and counterproductive work behavior", Frontiers in Psychology, Vol. 9, p. 1776.

Zhou, Z.E., Meier, L.L. and Spector, P.E. (2019), "The spillover effects of coworker, supervisor, and outsider workplace incivility on work-to-family conflict: a weekly diary design", Journal of Organizational Behavior, Vol. 40 No. 9-10, pp. 1000-1012.

\section{Further reading}

Alessandri, G., Borgogni, L. and Latham, G.P. (2017), “A dynamic model of the longitudinal relationship between job satisfaction and supervisor-rated job performance”, Applied Psychology, Vol. 66 No. 2, pp. 207-232.

Department of Economic and Social Affairs (2010), The World's Women, United Nations, New York, NY.

Rahim, M.A. (2001), Managing Conflict in Organizations, Transaction Publishers, NJ.

Shimazu, A., Schaufeli, W.B., Kamiyama, K. and Kawakami, N. (2015), "Workaholism vs. work engagement: the two different predictors of future well-being and performance", International Journal of Behavioral Medicine, Vol. 22 No. 1, pp. 18-23.

\section{Corresponding author}

Yasir Mansoor Kundi can be contacted at: yasir-kundi@hotmail.com

For instructions on how to order reprints of this article, please visit our website:

www.emeraldgrouppublishing.com/licensing/reprints.htm

Or contact us for further details: permissions@emeraldinsight.com 